\title{
Highlights from the 6th International Society for Computational Biology Student Council Symposium at the 18th Annual International Conference on Intelligent Systems for Molecular Biology
}

Christiaan Klijn ${ }^{1,2^{*}}$, Magali Michaut ${ }^{3,4}$, Thomas Abeel ${ }^{5,6}$

From Sixth International Society for Computational Biology (ISCB) Student Council Symposium Boston, MA, USA. 9 July 2010

\begin{abstract}
This meeting report gives an overview of the keynote lectures and a selection of the student oral and poster presentations at the 6th International Society for Computational Biology Student Council Symposium that was held as a precursor event to the annual international conference on Intelligent Systems for Molecular Biology (ISMB). The symposium was held in Boston, MA, USA on July 9th, 2010.
\end{abstract}

\section{Introduction}

The Student Council of the International Society for Computational Biology (ISCB) is a world-wide organization for students in computational biology and bioinformatics. The major aims of the Student Council are to organize events and facilitate networking opportunities for students. The main contribution of the Student Council is to nurture soft skills, such as working in a team, organizational and networking skills, to complement the normal academic program. Since its inception, the Student Council has organized an annual student symposium for the benefit of the student community. This year, the sixth ISCB Student Council Symposium was held in conjunction with the ISMB conference on July 9th. Over 110 delegates took part in this edition of the ISCB Student Council Symposium. The symposium opened with a scientific speed dating session to allow the delegates to get to know one another before the symposium kicked off. The program featured three

\footnotetext{
* Correspondence: c.klijn@nki.nl

'The Netherlands Cancer Institute, division of Molecular Biology, Amsterdam, The Netherlands

Full list of author information is available at the end of the article
}

keynote lectures, two partner presentations, twelve contributed student presentations and an extensive poster session with over 50 posters.

We were honoured to have three highly esteemed scientists deliver the keynote presentations. Gary Bader (University of Toronto, Canada) opened the scientific program with his presentation titled: 'Predicting proteinprotein interaction networks from the genome.' The afternoon session was initiated by Larry Hunter (University of Colorado, Denver, USA) with a presentation titled 'Thinking Big: How Artificial Intelligence and Molecular Biology can transform each other'. The final keynote lecture of the day was conducted by David Altshuler (The Broad Institute of MIT and Harvard, Boston, USA) and was titled 'Genomic Variation and the Inherited Basis of Common Disease'

This year we welcomed two talks by our industrial and research partners. Katrina Pavelin of the European Bioinformatics Institute (Cambridge, UK) gave an overview of training and career opportunities at EMBL-EBI. Joeri van der Velde of the University of Groningen (The Netherlands) introduced the Netherlands Bioinformatics Center (NBIC) and presented MOLGENIS, an environment 
for rapid generation of extensible software platforms for genotypes and phenotypes.

\section{Proceedings}

This year we received almost one hundred submissions from students to present their work at the symposium. These submissions were peer-reviewed by 30 independent reviewers from who the program committee selected 12 for oral presentation. An additional 55 abstracts were accepted to be presented in a poster. The twelve oral presentations fell into three main fields of research: Proteins, (Epi)Genomics and Bioinformatics of Health and Disease. Each of these topics featured a block of four presentations. Here we briefly discuss the presentations that are featured in this special proceedings issue.

\section{Proteins}

Bioinformatics has been used to study proteins and protein interactions for a long time. One of the main questions in protein bioinformatics has been how to spatially model interactions between different proteins. Vanhee et al. [1] presented a novel approach that does not use whole protein structures for predicting interactions, but instead focuses on the interaction modelling of fragments. This approach showed promise in being able to correctly predict many interactions, possibly simplifying the search for novel interactions. Li et al. [2] showed a different perspective on protein interactions. They modelled proteins in a crowed environment, which is the natural state in a cell, and were able to predict striking effects on protein-protein binding for both high and low affinity binding partners using their macromolecular crowding model.

The prediction of the three dimensional structure of a protein is another large field in protein bioinformatics. As the structure of a protein influences much of its function, an accurate estimation of its spatial conformation is essential. Shah et al. [3] presented a novel approach to find similarities between protein structures that are not necessarily evident from the amino acid sequences. In their feature-based search they found that the incorporation of secondary structures sped up the alignment of similar structure while remaining very accurate. Finding structurally similar proteins is an important endeavour. Finding the exact sites where the catalysed reactions take place is equally important. Xin et al. [4] presented a structure-based kernel approach to find novel catalytic residues in protein sequence. Their approach out-performed existing methods and could be used to associate mutations implicated in heritable disease to specific catalytic activities of the mutated proteins.

\section{(Epi)Genomics}

The field of (Epi)Genomics has exploded in scope in the last 10 to 15 years. The invention of the DNA micro array technique enabled large-scale investigations into gene expression, DNA structural changes, single-nucleotide variations in the human population and many other genome-wide assays. With the advent of new high throughput sequencing methods, the amount of data associated with studies into genomics has risen exponentially. The field of genomics data analysis will have to face this flood of new data [5].

With the newly acquired possibility to identity genome-wide patterns of chromatin modifications, analysis of genome-wide profiles of different modifications in the same samples poses an interesting challenge. Larson et al. [6] opened the (Epi)Genomics session with a new Hidden Markov Model based algorithm to find multigene domains from integrated ChIP-seq experiments. By combining the epigenetic profiles obtained from ChIPseq of five different histone modification marks they were able to identify large scale organization of gene clusters.

Single Nucleotide Polymorphisms (SNPs) have replaced old genomic markers in large studies to find genomic locations associated with disease. These Genome Wide Association Studies (GWAS) typically investigate a disease in a large case-control cohort. Surendran et al. [7] reported on a GWAS that compared 14,000 cases and 3,000 shared controls in which they found 53 new loci associated with seven common diseases. By using only the non-synonymous SNPs they were able to extract more associations than the original studies reported. Even if an informative SNP has been associated with a disease, finding the causative variation is still a difficult problem. Since many SNPs are co-inherited with neighbouring SNPs defining the actual nucleotide responsible for the disease is a difficult task. Macintyre et al. [8] presented a novel algorithm to predict causative SNPs by focusing on the SNPs that disrupt transcription factor binding sites.

With the influx of data as a result of the development of high throughput sequencing technologies comes the substantial task of making sense of it all. Using the data that is a result of RNA sequencing experiments Behr et al. [9] developed a novel gene finding algorithm, mGene.ngs. They showed that their algorithm is more accurate than previously developed approaches and has the added benefit of predicting alternative transcripts.

\section{Bioinformatics of Health and Disease}

Computational biology and bioinformatics have many applications in the field of health and disease. In this session, examples of the high diversity of possible studies 
were given. The presentations covered various topics, namely: metabolic modelling in heart disease, chemo informatics, anti-gen prediction and vaccine design. Hettling et al. [10] presented on applying a 'sloppy' modelling approach to metabolic data of the Creatine Kinase (CK) system in heart muscle. Using their approach, it was confirmed that CK acts as an energy buffer in the energy transport system of the heart muscle. Magariños et al. [11] continued with a description of tools implemented in the Tropical Disease Targets Database (tdrtargets.org). Using various features of novel chemical compounds they were able to make predictions for over 435,000 compounds to act on more than 3,500 clinically relevant targets. Carmona et al. [12] continued on the subject of pathogens in tropical disease. In this case they use novel approaches to predict potentially useful peptides useful as low cross-reactive antigens in diagnosis and treatment. They were successful in prioritizing peptides that were specific to positive serum samples. Banton et al. [13] wrapped up the proceedings part of the conference with a presentation on a bioengineering approach for vaccine design for the Ebola virus. Using mathematical models for predicting immune response efficacy and structure based epitope identification they were able to specify a peptide to use in Ebola vaccination.

\section{Posters}

Another 55 abstracts were presented in the form of a poster presentation. From these presentations a winner and a runner-up prize for best poster presentations was selected by collecting ballots from the attendees as well as judgment by an independent jury. Unfortunately, the winner declined to have the abstract published in these proceedings. The runner-up for best poster presentation was McDowall et al. [14] who reported on prediction of human protein-protein interactions.

\section{Conclusions}

Given the large number of abstracts submitted to the Student Council Symposium we were able to provide three high-quality student presentation sessions as well as an active and highly interactive poster session.

\section{The future}

The next Student Council Symposium is planned to be held together with ISMB/ECCB 2011 in Vienna. For information on the Student Council and other events we organize for students in computational biology and bioinformatics, please see our website: http://www.iscbsc.org.

\section{Acknowledgements}

The success of an event the size of the ISCB Student Council Symposium depends on the commitment of many. We would like to thank ISCB Executive Administrator BJ Morrison McKay, ISMB 2010 conference organizer
Steven Leard and ISCB Administrative Support Suzi Smith for their logistical support and invaluable advice. We deeply appreciate their continued support of the ISCB Student Council and the symposium.

We are also greatly indebted to ISMB 2010 conference chair Olga Troyanskaya and co-chairs Michal Linial and Jill Mesirov for giving us the opportunity to have the 6th ISCB Student Council Symposium in Boston. Further, we would like to acknowledge the support of the ISCB Board of Directors and their trust in our vision. The Student Council would also like to thank our keynote speakers Gary Bader, David Altshuler and Larry Hunter who are volunteering their time to contribute to the success of the symposium and to promote the next generation of computational biologists. We would like to thank everyone involved in the organization this year for their contribution. Furthermore, we would like to thank everyone on the program committee for their time and effort. We also thank the BMC Bioinformatics Editorial Office for their help in preparing this supplement. We are extremely grateful for the financial support that we received from our sponsors. Without their help many of the exciting opportunities that we offer to the delegates at the 6th ISCB Student Council Symposium would not have been possible. The 6th ISCB Student Council Symposium was made possible through generous financial support from the European Bioinformatics Institute, Wellcome Trust for travel fellowships, lowa State University, Netherlands Bioinformatics Centre, Institute for Systems Biology, New England BioLabs, Broad Institute, National Center for Integrative Biomedical Informatics and BMC Bioinformatics. The organizers are also grateful to Oxford University Press for sponsoring the best poster and best presentation awards

\section{Author details}

${ }^{1}$ The Netherlands Cancer Institute, division of Molecular Biology, Amsterdam, The Netherlands. ${ }^{2}$ The Bioinformatics Lab, Faculty of Electrical Engineering, Delft University of Technology, Delft, The Netherlands. ${ }^{3}$ Donnelly Centre for Cellular and Biomolecular Research, University of Toronto, Ontario, Canada. ${ }^{4}$ Banting and Best Department of Medical Research, University of Toronto, Ontario, Canada. ${ }^{5}$ Department of Plant Systems Biology, VIB, Ghent University, Gent, Belgium. 'Broad Institute of MIT and Harvard, Cambridge, MA, USA.

Published: 7 December 2010

\section{References}

1. Vanhee P, Stricher F, Baeten L, Verschueren E, Serrano L, Rousseau F, Schymkowitz J: Modeling protein-peptide interactions using protein fragments: fitting the pieces? BMC Bioinformatics 2010, 11(Suppl 4):01.

2. Li XF, Moal $H$, Bates PA: Bridging the Gaps: Atomic Simulation of Macromolecular Environment Brings Together Protein Docking, Interaction Kinetics and the Crowding Effects. BMC Bioinformatics 2010, 11(Suppl 10):O2.

3. Shah S, Sahinidis N: Exploiting physical properties in protein structure alignment. BMC Bioinformatics 2010, 11(Suppl 10):03.

4. Xin F, Myers S, Li YF, Cooper DN, Mooney SD, Radivojac P: Structure-based kernels for the prediction of catalytic residues and their involvement in human inherited disease. BMC Bioinformatics 2010, 11(Suppl 10):04.

5. Abeel T, Ridder J, Peixoto L: Highlights from the 5th International Society for Computational Biology Student Council Symposium at the 17th Annual International Conference on Intelligent Systems for Molecular Biology and the 8th European Conference on Computational Biology. BMC Bioinformatics 2009, 10(Suppl 13):11.

6. Larson J, Yuan G: A hidden Markov model for detecting multi-gene chromatin domains. BMC Bioinformatics 2010, 11(Suppl 10):O5.

7. Surendran P, Stanton A, Shields D: Genome wide association study of nonsynonymous Single Nucleotide Polymorphisms for seven common diseases. BMC Bioinformatics 2010, 11(Suppl 10):06.

8. Macintyre G, Bailey J, Haviv I, Kowalczyk A: is-rSNP: A novel technique for in silico regulatory SNP detection. BMC Bioinformatics 2010, 11(Suppl 10): O7.

9. Behr J, Bohnert R, Zeller G, Schweikert G, Hartmann L, Rätsch G: Next Generation Genome Annotation with mGene.ngs. BMC Bioinformatics 2010, 11(Suppl 10):O8.

10. Hettling $\mathrm{H}$, Heringa J, van Beek JHGM: Analysis of the functional properties of the creatine kinase system using a multiscale 'sloppy' modeling approach. BMC Bioinformatics 2010, 11(Suppl 10):O9. 
11. Magariños MP, Overington J, Carmona S, Shanmugam D, Doyle M, Ralph S, Crowther G, Hertz-Fowler C, Nwaka S, Berriman M, Roos D, Van Voorhis W, Agüero F: Designing and implementing chemoinformatic approaches in TDR Targets Database: linking genes to chemical compounds in tropical disease causing pathogens. BMC Bioinformatics 2010, 11(Suppl 10):010.

12. Carmona S, Sartor P, Leguizamón S, Campetella O, Agüero F: A computational pipeline for diagnostic biomarker discovery in the human pathogen Trypanosoma cruzi. BMC Bioinformatics 2010, 11(Suppl 10):011.

13. Banton S, Roth Z, Pavlovic M: A bioengineering approach for rational vaccine design towards the Ebola Virus. BMC Bioinformatics 2010, 11(Suppl 10):012.

14. McDowall M, Scott MS, Barton GJ: Human Protein-Protein Interaction Prediction. BMC Bioinformatics 2010, 11(Suppl 10):P1.

doi:10.1186/1471-2105-11-S10-11

Cite this article as: Klijn et al:: Highlights from the 6th International Society for Computational Biology Student Council Symposium at the 18th Annual International Conference on Intelligent Systems for Molecular Biology. BMC Bioinformatics 2010 11(Suppl 10):11.

\section{Submit your next manuscript to BioMed Central} and take full advantage of:

- Convenient online submission

- Thorough peer review

- No space constraints or color figure charges

- Immediate publication on acceptance

- Inclusion in PubMed, CAS, Scopus and Google Scholar

- Research which is freely available for redistribution

Submit your manuscript at www.biomedcentral.com/submit
C Biomed Central 